\title{
A study concerning morphometry of abdominal aorta branches and abdominal viscera: relations and correlations
}

\author{
A. Michalinos ${ }^{1}$, N. Goutas ${ }^{2}$, Ch. Spiliopoulou ${ }^{2}$, N. Nikiteas ${ }^{3}$, P. Skandalakis ${ }^{1}$, \\ V. Gorgoulis ${ }^{4}$, T. Troupis ${ }^{1}$ \\ ${ }^{1}$ Department of Anatomy, Faculty of Medicine, National and Kapodistrian University of Athens, Greece \\ ${ }^{2}$ Department of Forensic Medicine and Toxicology, National and Kapodistrian University of Athens, Greece \\ ${ }^{3} 2^{\text {nd }}$ Department of Surgery, National and Kapodistrian University of Athens, Greece \\ ${ }^{4}$ Department of Histology and Embryology, National and Kapodistrian University of Athens, Greece
}

[Received: 10 March 2015; Accepted: 28 May 2015]

\begin{abstract}
Research interest on abdominal aorta branches and abdominal viscera morphometry is renewed by technological evolution and development of new radiologic and clinical applications including stent grafts and chemoembolisation materials. Despite that, data on morphometry of abdominal aorta branches and abdominal viscera are lacking. To investigate this subject authors performed a morphometric study on 50 adult fresh and embalmed Caucasian cadavers and examined abdominal aorta branches', kidney and spleen morphometry. Our results on arteries' morphometry did not differ significantly from those of the literature; yet, we discovered significant differences between fresh and embalmed cadavers on viscera morphometry, spleen and kidneys. We also found previously unreported correlations between abdominal aorta branches' morphometric characteristics. Even more, we identified correlations between regional arteries and viscera morphometric characteristics, proposing a new factor determining viscera development. Finally, we performed an extensive literature review so to place our results in an anatomic, embryologic and, even more, a clinical context. We believe that our results add knowledge on abdominal aorta branches and viscera morphometry and are valuable for clinical, radiological and surgical applications including visceral arteries' aneurysms investigation and treatment, chemoembolisation procedures, stent grafts design and transplantation. (Folia Morphol 2016; 75; 1: 60-75)
\end{abstract}

Key words: abdominal aorta, spleen, kidney, morphometry, aneurysm, correlation

\section{INTRODUCTION}

Despite their value for basic, radiological, clinical and surgical applications existing data on morphometry of abdominal aorta (AA) branches and abdominal viscera are scarce.
Only few studies investigate all AA branches $[20,29,45,55,69,72]$. Concerning methodology, most studies use either unselected autopsy material and their results are influenced by inclusion of many diseased subjects or use radiological methods and thus

Address for correspondence: Dr T.G. Troupis, Department of Anatomy, Faculty of Medicine, National and Kapodistrian University of Athens, 75 Mikras Asias str., 11527 Athens, Greece, tel: +30-210-7462388, fax:+30-210-7462398, e-mail: ttroupis@gmail.com; ttroupis@med.uoa.gr 
are prone to their technical limitations. Strict inclusion criteria and standardised methodology have been used in only few studies $[28,60]$.

Precise morphometric data are important for anatomic and physiological studies. Blood flow to an organ is a derivative of diameter of its arteries, while nutritional and functional status depends partly on blood flow [7]. Embryologic mechanisms determining arteries' development, including diameter, are only partially known and probably multi-factorial $[79,102]$.

Apart from their undisputable anatomical and embryological interest, those data are also valuable for many clinical, interventional and surgical procedures. Stent grafts design and placement for endovascular repair of AA and branches aneurysms $[38,40]$, chemoembolisation for haemorrhage or chemotherapy [5], visceral aneurysm diagnosis and treatment [8] and transplantation $[36,87]$ are based on precise calculation of AA branches' diameters. Diagnosis, staging and treatment of many relative common diseases including chronic mesenteric ischaemia or other occlusive diseases of AA branches [25] and chronic renal insufficiency [3] utilise such measurements. Certain morphometric characteristics including volume and length are useful for diagnosis and staging of spleen and kidney diseases like splenomegaly and various nephropathies [7, 9]. Exact knowledge of these values would ameliorate interpretation of diagnostic tests and probably lead to design of new ones.

Considering those, purpose of this study is to (1) provide accurate data on AA branches' morphometric values; (2) study correlations and intra correlations between AA branches and abdominal viscera, especially kidney and spleen; (3) attempt interpretation of these results in an anatomical and embryological context; and (4) investigate possible clinical, interventional and surgical applications.

\section{MATERIALS AND METHODS}

Between 2010 and 2013, 50 adult Caucasian (Hellenic) cadavers were prospectively studied. Characteristics evaluated were diameter of $A A$ and celiac artery (CA) branches, morphometry of abdominal viscera and their correlations. Twelve cadavers were embalmed from Department of Anatomy of National and Kapodistrian University of Athens, Greece and 38 were fresh, subjected to autopsy, from Department of Forensic Medicine and Toxicology. The research protocol had been submitted and approved by the ethics committee of our institution.
For fresh cadavers, strict selection criteria were applied so to ensure normality and suitability for an anatomic study. Exclusion criteria were previous operation or injury in abdominal area, intra-abdominal neoplasm, AA aneurysm, atheromatosis, any disease known to affect arteries (e.g. diabetes mellitus, vasculiitis and hypertension) or diseases of abdominal viscera (e.g. large kidney cysts, glomerulonephritis, marked splenomegaly). Subjects with known heart, liver or renal failure or hospitalised before death were also excluded. Autopsy should be performed less than $24 \mathrm{~h}$ after documented time of death. No age criterion was applied. Embalmed cadavers were considered "normal" and thus suitable for anatomical study after review of their medical history and careful inspection of the abdomen for the above mentioned conditions.

After enrolment in the study sex, age and height of each cadaver was recorded. Abdominal aorta was dissected through a midline incision from diaphragm to aortic bifurcation. If necessary, subcostal or inguinal incisions were also performed for better exposure of abdominal contents. A combined approach was adopted for exposure of the whole AA. Dissection of infrarenal aorta began with incision of parietal peritoneum in the midline and followed by sharp and blunt dissection so to reveal origins of iliac arteries, inferior mesenteric artery (IMA) and renal arteries. Gonadal arteries thought not subject of the study were also dissected and preserved. Arteries were dissected for at least $1 \mathrm{~cm}$ from their origin. For suprarenal aorta, pancreas was gently elevated so to identify superior mesenteric artery (SMA) and splenic artery (SA). Left gastric artery was dissected at lesser curvature of the stomach and followed at its origin. Gastrocolic ligament was incised so to gain entrance at lesser omental bursa, superior pancreas border and origin of CA. After its identification, common hepatic artery was identified and dissected. During dissection, great care was taken so not to injure any of the arteries or their branches. Extensive traction that could alter arteries morphometry was also avoided. Arteries courses were kept as dissected. Final dissection result is presented at Figures 1 and 2 . From abdominal viscera, spleen and kidneys were subjected to study. Spleen was sharply detached from its adhesions and vessels were divided right at hilum. Kidneys were also sharply detached and vessels were divided at hilum after dissection of ureters for $2-3 \mathrm{~cm}$. If anatomic variations incompatible with purpose of this study (e.g. double renal arteries, common origin 


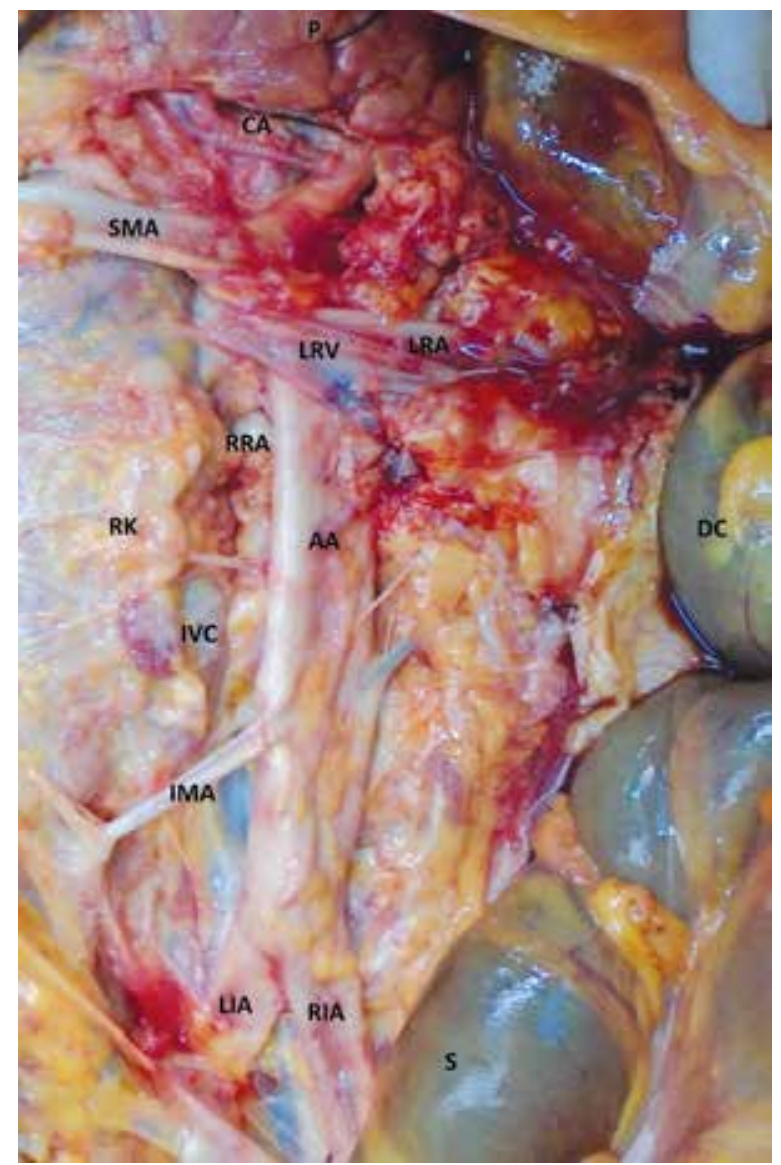

Figure 1. Abdominal aorta (AA) dissection in corpus; IVC - inferior vena cava; $C A$ - celiac artery; SMA — superior mesenteric artery; RRA — right renal artery; LRA — left renal artery; IMA — inferior mesenteric artery; RIA — right iliac artery; LIA — left iliac artery; DC - descending colon; S - sigmoid; $\mathrm{P}$ - pancreas; RK — right kidney; LRV — left renal vein.

of SMA and CA, accessory spleens, horseshoe kidney) were encountered, cadavers were excluded.

After dissection was complete and photographs were taken, arteries were cut at least $1 \mathrm{~cm}$ from their origin. Lumbar arteries were also cut and aorta was freed and transferred in a laboratory bench. While aorta was dissected in situ so to achieve identification of every variation and avoid extensive trauma that could alter arteries' morphometry, measurements were performed ex situ (Fig. 3) so to achieve precision and repeatability. Diameter of CA, SA, left gastric artery, common hepatic artery, SMA, right renal artery (RRA), left renal artery (LRA), IMA, right iliac artery and left iliac artery were recorded with the use of an electronic Vernier calliper (accuracy: $\pm 0.01 \mathrm{~mm}$ ). Diameter was recorded at a point perpendicular to longitudinal axis of the arteries approximately $0.5 \mathrm{~cm}$ from its origin.

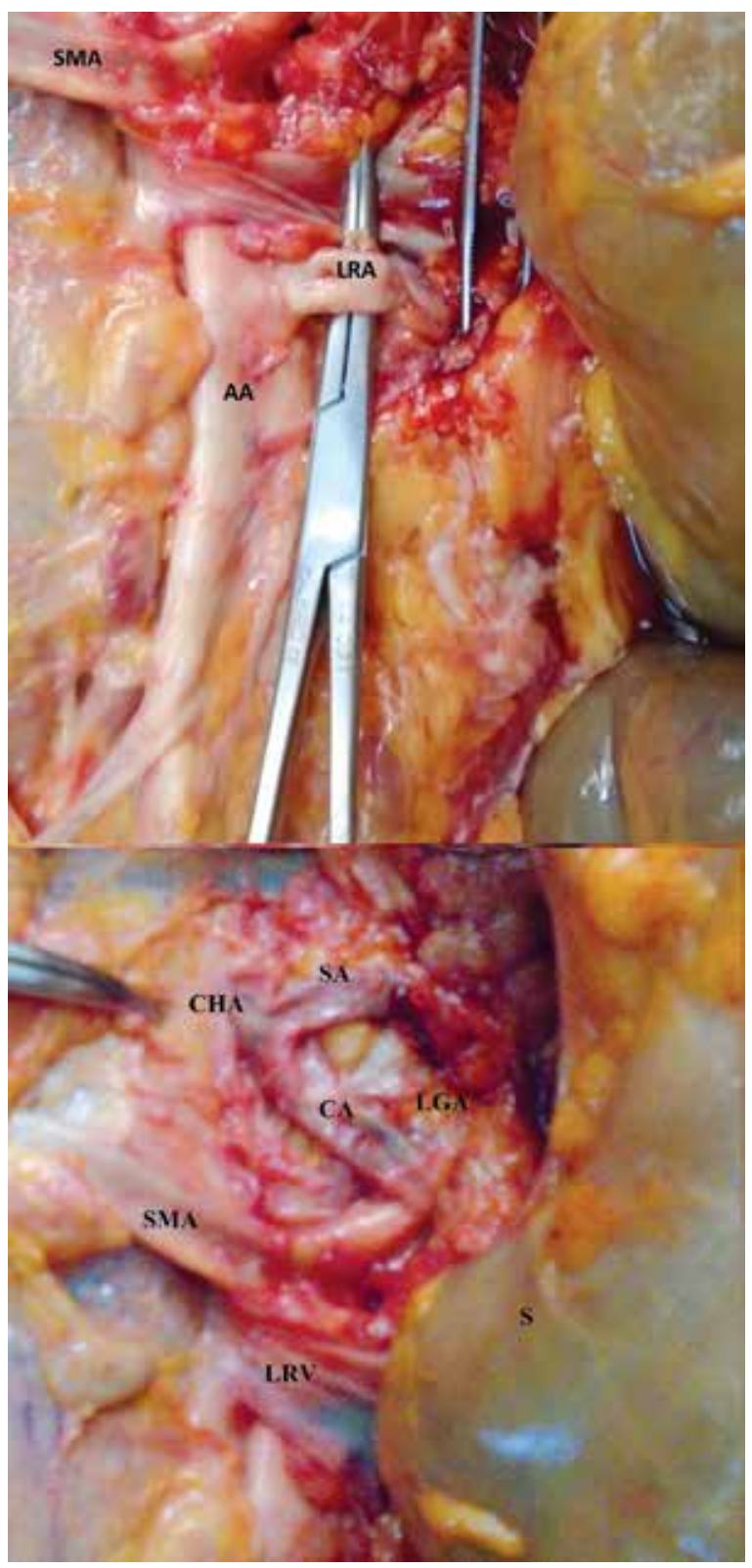

Figure 2. Celiac artery $(C A)$ and left renal artery dissection in corpus; AA — abdominal aorta; SMA — superior mesenteric artery; SA — splenic artery; CHA — common hepatic artery; LGA — left gastric artery; LRA — left renal artery; S — stomach.

Spleen and kidney were weighted with an electronic scale (accuracy: $\pm 2 \mathrm{~g}$ ) and their length, width and thickness were recorded. Weight measurements were not performed at embalmed cadavers due to unknown effect of formaldehyde at viscera weight. For spleen, "length" was defined as maximum distance between its upper and lower border, "thickness" as the distance between arteries' entrance at hilum and its convex border, perpendicular to length axis, 


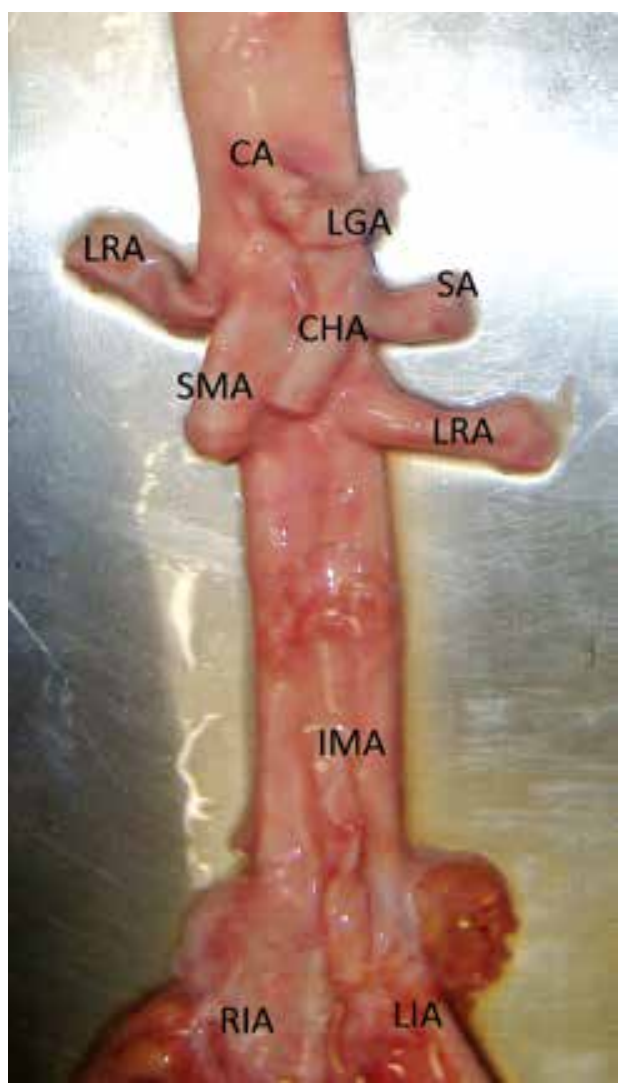

Figure 3. Abdominal aorta dissection ex corpus; $\mathrm{CA}$ - celiac artery; SA — splenic artery; CHA - common hepatic artery; LGA left gastric artery; SMA — superior mesenteric artery; LRA — left renal artery; IMA — inferior mesenteric artery; RIA — right iliac artery; LIA — left iliac artery. and "width" as the distance between its front and back border at hilum level, perpendicular to thickness axis. The same definitions were used for right and left kidneys (Fig. 4).

\section{Statistical analysis}

Results were recorded in forms of tables and subjected to statistical analysis with the purpose of identifying relations and correlations between them. Data were complete for all specimens (with the exception of weight of abdominal viscera for embalmed cadavers). Statistical analysis was performed with SPSS 15.0. All values were checked for normality and found normal and thus parametrical tests only were used. Results are presented as mean \pm standard deviation, unless otherwise stated. Comparisons are performed with 2-tailed Student's test setting level of statistical significance at 0.05 . Correlations are performed with the use of Pearson's correlation coefficient ( $r$ ).

\section{RESULTS}

Abdominal aorta branches diameters and viscera morphometric characteristics for the whole sample and stratified by sex and embalmment are presented at Table 1.

Mean age of our sample was $65.9 \pm 21.4$ year; lower that life expectancy in Greece (approximately 80 years) due to inclusion of violent deaths and suicides, com-

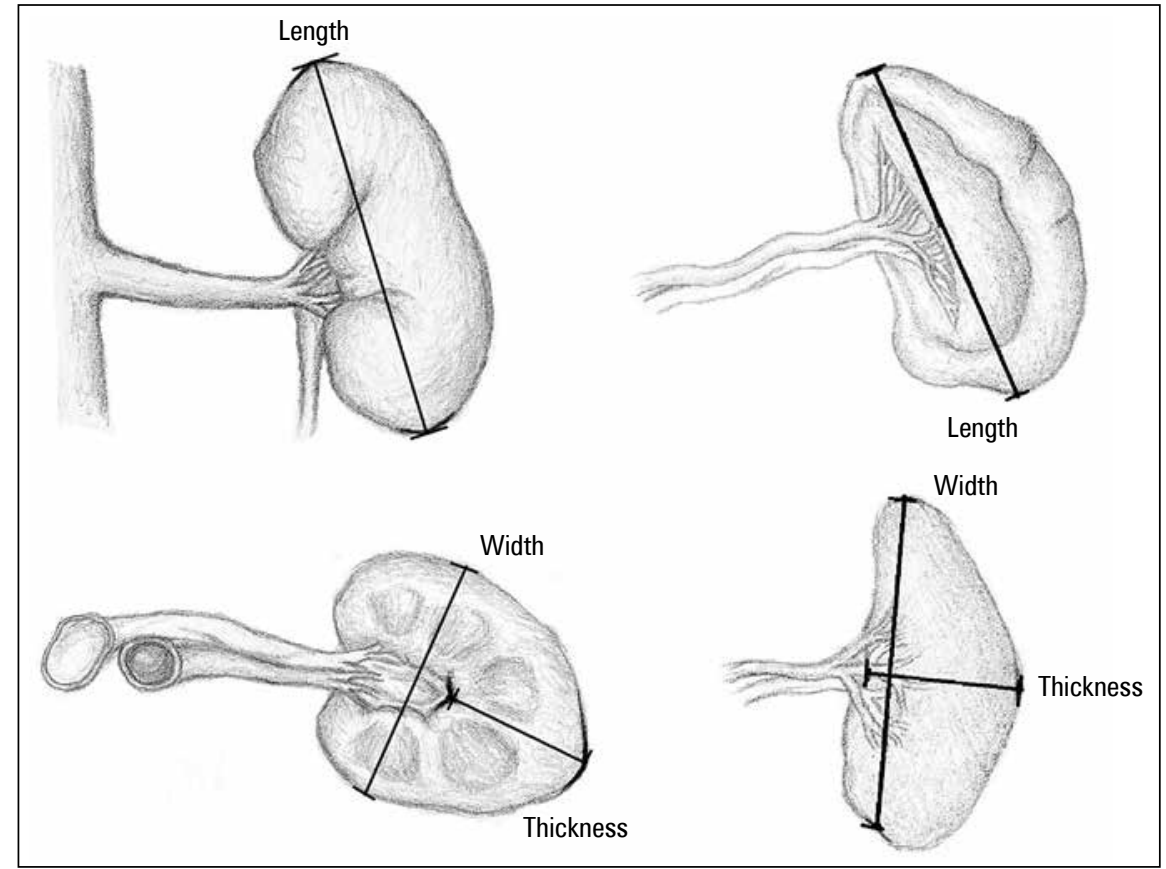

Figure 4. Spleen and kidney measurements definitions. 
Table 1. Morphometric values of abdominal aorta branches, kidney and spleen

\begin{tabular}{|c|c|c|c|c|c|c|c|}
\hline & Total & Men & Women & $\mathbf{P}$ & Fresh & Embalmed & $\mathbf{P}$ \\
\hline$n$ & 50 & 34 & 16 & & 38 & 12 & \\
\hline Age [years] & $65.9 \pm 21.4$ & $56.06 \pm 19.7$ & $76.0 \pm 15.8$ & $<0.01$ & $59.19 \pm 21.6$ & $73.25 \pm 14.2$ & $<0.05$ \\
\hline Height $[\mathrm{cm}]$ & $1.68 \pm 0.1$ & $1.71 \pm 0.1$ & $1.63 \pm 0.1$ & $<0.05$ & $1.69 \pm 0.1$ & $1.65 \pm 0.1$ & $>0.05$ \\
\hline $\mathrm{CA}[\mathrm{mm}]$ & $8.57 \pm 1.57$ & $8.81 \pm 1.7$ & $8.04 \pm 1.2$ & $>0.05$ & $8.64 \pm 1.6$ & $8.2 \pm 1.5$ & $>0.05$ \\
\hline SA [mm] & $6.44 \pm 1.4$ & $6.49 \pm 1.4$ & $6.36 \pm 1.4$ & $>0.05$ & $6.33 \pm 1.3$ & $6.75 \pm 1.5$ & $>0.05$ \\
\hline CHA [mm] & $5.74 \pm 2.0$ & $5.68 \pm 1.8$ & $4.09 \pm 1.3$ & $>0.05$ & $5.37 \pm 1.4$ & $6.75 \pm 2.2$ & 0.04 \\
\hline LGA [mm] & $3.89 \pm 1.6$ & $3.80 \pm 2.2$ & $5.83 \pm 1.6$ & $>0.05$ & $3.81 \pm 1.4$ & $4.12 \pm 1.8$ & $>0.05$ \\
\hline SMA [mm] & $8.35 \pm 1.6$ & $8.24 \pm 1.7$ & $8.44 \pm 1.5$ & $>0.05$ & $8.38 \pm 1.8$ & $8.23 \pm 1.2$ & $>0.05$ \\
\hline $\mathrm{RRA}[\mathrm{mm}]$ & $7.13 \pm 1.2$ & $7.35 \pm 1.2$ & $6.75 \pm 1.0$ & $>0.05$ & $7.23 \pm 1.2$ & $6.83 \pm 1.2$ & $>0.05$ \\
\hline LRA [mm] & $7.03 \pm 1.4$ & $7.08 \pm 1.6$ & $6.73 \pm 1.1$ & $>0.05$ & $7.17 \pm 1.6$ & $6.50 \pm 0.5$ & $>0.05$ \\
\hline IMA [mm] & $4.21 \pm 1.2$ & $4.01 \pm 2.4$ & $4.49 \pm 0.8$ & $>0.05$ & $4.08 \pm 1.2$ & $4.73 \pm 0.9$ & $>0.05$ \\
\hline RIA [mm] & $12.23 \pm 2.4$ & $12.08 \pm 1.6$ & $12.56 \pm 2.1$ & $>0.05$ & $11.75 \pm 2.4$ & $13.6 \pm 2.1$ & $>0.05$ \\
\hline LIA [mm] & $11.77 \pm 2.2$ & $11.51 \pm 2.3$ & $12.31 \pm 1.9$ & $>0.05$ & $11.35 \pm 2.1$ & $13.10 \pm 2.1$ & $>0.05$ \\
\hline SWe [g] & $173.78 \pm 94.6$ & $194.44 \pm 100.4$ & $118.18 \pm 37.4$ & $<0.05$ & $173.78 \pm 94.1$ & N/A & - \\
\hline SLe [cm] & $11.69 \pm 2.1$ & $12.18 \pm 2.2$ & $10.71 \pm 1.6$ & $<0.05$ & $12.27 \pm 2.1$ & $9.95 \pm 0.1$ & $<0.01$ \\
\hline SWi [cm] & $7.54 \pm 1.6$ & $7.69 \pm 1.8$ & $7.23 \pm 0.9$ & $>0.05$ & $7.82 \pm 1.7$ & $6.70 \pm 0.8$ & $<0.05$ \\
\hline STh [cm] & $4.20 \pm 1.3$ & $4.32 \pm 1.3$ & $3.96 \pm 1.5$ & $>0.05$ & $4.47 \pm 1.3$ & $3.78 \pm 1.2$ & $<0.05$ \\
\hline RKWe [g] & $154 \pm 53.8$ & $160.71 \pm 52.2$ & $142.73 \pm 58.2$ & $>0.05$ & $154.21 \pm 53.8$ & $\mathrm{~N} / \mathrm{A}$ & - \\
\hline RKLe [cm] & $11.01 \pm 2.1$ & $11.48 \pm 1.8$ & $10.04 \pm 2.6$ & $<0.05$ & $11.85 \pm 1.5$ & $8.45 \pm 1.9$ & $<0.01$ \\
\hline RKWi [cm] & $5.13 \pm 1.6$ & $5.32 \pm 2.6$ & $4.74 \pm 1.5$ & $>0.05$ & $5.57 \pm 1.5$ & $3.78 \pm 0.8$ & $<0.05$ \\
\hline RKTh [cm] & $4.42 \pm 1.2$ & $4.75 \pm 0.9$ & $3.73 \pm 1.3$ & $<0.05$ & $4.66 \pm 1.0$ & $3.72 \pm 1.2$ & $<0.01$ \\
\hline LKWe [g] & $155.53 \pm 46.8$ & $163.57 \pm 39.7$ & $138.18 \pm 58.8$ & $>0.05$ & $155.53 \pm 46.8$ & $\mathrm{~N} / \mathrm{A}$ & - \\
\hline LKLe [cm] & $11.43 \pm 2.0$ & $11.61 \pm 2.0$ & $10.91 \pm 2.0$ & $>0.05$ & $12.10 \pm 1.5$ & $8.30 \pm 0.7$ & $<0.01$ \\
\hline LKWi [cm] & $5.15 \pm 1.1$ & $5.17 \pm 1.9$ & $5.08 \pm 1.0$ & $>0.05$ & $5.27 \pm 1.2$ & $4.58 \pm 0.7$ & $<0.05$ \\
\hline LKTh [cm] & $4.60 \pm 1.2$ & $4.71 \pm 1.1$ & $4.29 \pm 1.4$ & $>0.05$ & $4.76 \pm 1.1$ & $3.93 \pm 1.0$ & $<0.05$ \\
\hline
\end{tabular}

Statistical important differences are presented in bold; CA — celiac artery; SA — splenic artery; CHA — common hepatic artery; LGA — left gastric artery; SMA — superior mesenteric artery; RRA — right renal artery; LRA — left renal artery; IMA — inferior mesenteric artery; RIA — right iliac artery; LIA — left liliac artery; SWe — spleen weight; SLe — spleen length; SWi — spleen width; STh — spleen thickness; RKWe - right kidney weight; RKLe — right kidney length; RKWi — right kidney width; RKTh — right kidney thickness; LKWe — left kidney weight; LKLe — left kidney length; LKWi — left kidney width; LKTh — left kidney thickness; N/A - not available

moner at younger ages and male sex. When stratified for fresh and embalmed cadavers, the latter's mean age was $76.0 \pm 15.8$, similar to life expectancy in Greece.

No statistically significant differences were noted between men and women and fresh and embalmed cadavers for AA branches' diameter. To the best of our knowledge, those data had never been compared before. While men showed a general trend for larger AA branches' diameter, this was not true for all cases and neither reached statistical significance for any AA branch; thus, in the context of this study, no morphometric differences for sex can be evidenced. Spleen weight, spleen length, right kidney length and thickness were significantly higher in men than women. Other viscera' morphometric characteristics showed the same tendency but did not reach statistical significance, probably due to small sample size.
When compared, $p$-value for right kidney weight was 0.07 , indicative of statistically significant difference.

No statistically significant differences were found in AA branches' diameter between fresh and embalmed cadavers. Most morphometric data derive from cadaveric studies and accept that embalmment does not affect arteries' morphometry. This assumption proves true at least for arteries' diameter. However all viscera morphometric characteristics were larger for fresh than embalmed cadavers, probably due to embalmment procedure and known dehydrating effect of formaldehyde.

Pearson's correlation coefficient between AA branches is depicted in Table 2. Notably all CA branches are intra-correlated as with $\mathrm{CA}$, with correlation coefficients ranging from 0.3 to 0.6 , exhibiting a homogeny for this arterial system. Superior mesenteric 
Table 2. Pearson's correlation coefficient between abdominal artery diameters (whole sample)

\begin{tabular}{|c|c|c|c|c|c|c|c|c|c|c|}
\hline & CA & SA & LGA & CHA & SMA & RRA & LRA & IMA & RIA & LIA \\
\hline CA & 1.00 & & & & & & & & & \\
\hline SA & 0.72 & 1.00 & & & & & & & & \\
\hline LGA & 0.35 & 0.29 & 1.00 & & & & & & & \\
\hline CHA & 0.50 & 0.57 & 0.40 & 1.00 & & & & & & \\
\hline SMA & 0.34 & 0.05 & 0.11 & 0.18 & 1.00 & & & & & \\
\hline RRA & 0.15 & 0.05 & 0.13 & 0.09 & 0.03 & 1.00 & & & & \\
\hline LRA & -0.15 & -0.14 & 0.09 & -0.17 & -0.02 & 0.34 & 1.00 & & & \\
\hline IMA & 0.02 & 0.14 & 0.04 & 0.14 & 0.07 & -0.05 & 0.23 & 1.00 & & \\
\hline RIA & 0.36 & 0.40 & 0.16 & 0.41 & 0.51 & 0.34 & 0.12 & 0.50 & 1.00 & \\
\hline LIA & 0.33 & 0.36 & 0.23 & 0.40 & 0.31 & 0.17 & 0.00 & 0.48 & 0.72 & 1.00 \\
\hline
\end{tabular}

Statistical important values are presented in bold; CA — celiac artery; SA — splenic artery; LGA — left gastric artery; CHA — common hepatic artery; SMA — superior mesenteric artery; RRA — right renal artery; LRA — left renal artery; IMA — inferior mesenteric artery; RIA — right iliac artery; LIA — left iliac artery

Table 3. Pearson's correlation coefficient between artery diameters stratified for embalmed/fresh cadaver

\begin{tabular}{|c|c|c|c|c|c|c|c|c|c|c|}
\hline & CA & SA & LGA & CHA & SMA & RRA & LRA & IMA & RIA & LIA \\
\hline CA & 1.00 & & & & & & & & & \\
\hline \multirow[t]{2}{*}{ SA } & 0.72 & 100 & & & & & & & & \\
\hline & 0.84 & 1.00 & & & & & & & & \\
\hline \multirow[t]{2}{*}{ LGA } & 0.30 & 0.26 & 100 & & & & & & & \\
\hline & 0.51 & 0.32 & 1.00 & & & & & & & \\
\hline \multirow[t]{2}{*}{ CHA } & 0.60 & 0.53 & 0.51 & 100 & & & & & & \\
\hline & 0.48 & 0.64 & 0.40 & 1.00 & & & & & & \\
\hline \multirow[t]{2}{*}{ SMA } & 0.28 & -0.05 & -0.02 & 0.19 & 100 & & & & & \\
\hline & 0.85 & 0.75 & 0.11 & 0.51 & 1.00 & & & & & \\
\hline \multirow[t]{2}{*}{ RRA } & 0.01 & 0.06 & -0.04 & 0.06 & -0.01 & 100 & & & & \\
\hline & 0.50 & 0.09 & 0.13 & 0.38 & 0.35 & 1.00 & & & & \\
\hline \multirow[t]{2}{*}{ LRA } & -0.22 & -0.14 & 0.12 & -0.20 & -0.05 & 0.33 & 100 & & & \\
\hline & 0.24 & -0.09 & 0.09 & 0.38 & 0.37 & 0.83 & 1.00 & & & \\
\hline \multirow[t]{2}{*}{ IMA } & -0.02 & -0.02 & 0.08 & -0.03 & 0.04 & 0.05 & 0.26 & 1.00 & & \\
\hline & 0.52 & 0.67 & 0.04 & 0.72 & 0.89 & -0.39 & 0.32 & 1.00 & & \\
\hline \multirow[t]{2}{*}{ RIA } & 0.33 & 0.31 & -0.07 & 0.22 & 0.56 & 0.36 & 0.16 & 0.43 & 1.00 & \\
\hline & 0.72 & 0.54 & 0.16 & 0.73 & 0.84 & 0.64 & 0.74 & 0.77 & 1.00 & \\
\hline \multirow[t]{2}{*}{ LIA } & 0.28 & 0.19 & 0.10 & 0.18 & 0.36 & 0.09 & 0.11 & 0.52 & 0.71 & 1.00 \\
\hline & 0.73 & 0.54 & 0.23 & 0.72 & 0.49 & 0.73 & 0.2 & -0.01 & 0.61 & 1.00 \\
\hline
\end{tabular}

Statistical important differences are presented in bold; CA — celiac artery; SA — splenic artery; LGA — left gastric artery; CHA — common hepatic artery; SMA — superior mesenteric artery; RRA — right renal artery; LRA — left renal artery; IMA — inferior mesenteric artery; RIA — right iliac artery; LIA — left iliac artery

artery diameter is correlated to CA diameter $(r=0.34$, $\mathrm{p}<0.05)$. Inferior mesenteric artery diameter shows no correlation to any other aorta branches as do renal arteries, excepted between them $(r=0.30$, $p<0.05)$. Notably iliac arteries are correlated to most other aorta branches with correlation coefficient from 0.31 to 0.50 . Probably those major branches are morphometric indices themselves.
Table 3 shows correlation coefficients stratified for embalmed and fresh cadavers. Notably in fresh cadavers correlation between SMA and CA enhances $(r=0.85, p<0.05)$ and strong correlations between SMA and IMA $(r=0.9, p<0.05)$ as between RRA and LRA occur ( $r=0.77, p<0.05$ ). Further interpretation is difficult, considering the relatively small sample size. In Table 4 same data stratified for sex are 
Table 4. Pearson's correlation coefficient between artery diameters stratified for men/women

\begin{tabular}{|c|c|c|c|c|c|c|c|c|c|c|}
\hline & CA & SA & LGA & CHA & SMA & RRA & LRA & IMA & RIA & LIA \\
\hline \multirow[t]{2}{*}{ CA } & 1.00 & & & & & & & & & \\
\hline & 1.00 & & & & & & & & & \\
\hline \multirow[t]{2}{*}{ SA } & 0.74 & & & & & & & & & \\
\hline & 0.75 & 1.00 & & & & & & & & \\
\hline \multirow[t]{2}{*}{ LGA } & 0.48 & 0.33 & 1.00 & & & & & & & \\
\hline & 0.01 & 0.25 & 1.00 & & & & & & & \\
\hline \multirow[t]{2}{*}{ CHA } & 0.66 & 0.63 & 0.41 & 1.00 & & & & & & \\
\hline & 0.13 & 0.42 & 0.38 & 1.00 & & & & & & \\
\hline \multirow[t]{2}{*}{ SMA } & 0.28 & -0.09 & 0.25 & 0.23 & 1.00 & & & & & \\
\hline & 0.61 & 0.36 & -0.34 & 0.03 & 1.00 & & & & & \\
\hline \multirow[t]{2}{*}{ RRA } & 0.10 & 0.08 & 0.10 & 0.23 & 0.02 & 1.00 & & & & \\
\hline & 0.03 & -0.06 & 0.33 & -0.25 & 0.17 & 1.00 & & & & \\
\hline \multirow[t]{2}{*}{ LRA } & -0.18 & -0.16 & 0.06 & -0.15 & -0.05 & 0.32 & 1.00 & & & \\
\hline & -0.12 & -0.11 & 0.17 & -0.24 & 0.12 & 0.48 & 1.00 & & & \\
\hline \multirow[t]{2}{*}{ IMA } & 0.05 & 0.08 & -0.07 & 0.10 & 0.07 & 0.14 & 0.27 & 1.00 & & \\
\hline & 0.22 & 0.32 & 0.37 & 0.24 & -0.03 & -0.35 & 0.04 & 1.00 & & \\
\hline \multirow[t]{2}{*}{ RIA } & 0.41 & 0.42 & 0.29 & 0.44 & 0.50 & 0.43 & 0.09 & 0.54 & 1.00 & \\
\hline & 0.32 & 0.37 & -0.32 & 0.30 & 0.56 & 0.23 & 0.28 & 0.28 & 1.00 & \\
\hline \multirow[t]{2}{*}{ LIA } & 0.35 & 0.35 & 0.26 & 0.43 & 0.35 & 0.25 & 0.13 & 0.54 & 0.82 & 1.00 \\
\hline & 0.50 & 0.43 & 0.07 & 0.29 & 0.19 & 0.18 & -0.46 & 0.14 & 0.38 & 1.00 \\
\hline
\end{tabular}

Statistical important differences are presented in bold; CA — celiac artery; SA — splenic artery; CHA — common hepatic artery; LGA — left gastric artery; SMA — superior mesenteric artery; RRA — right renal artery; LRA — left renal artery; IMA — inferior mesenteric artery; RIA — right iliac artery; LIA — left iliac artery

Table 5. Pearson's correlation coefficient between artery diameter and organ morphometry (whole sample)

\begin{tabular}{lcccc}
\hline & Weight & Length & Width & Thickness \\
\hline Splenic artery & $\mathbf{0 . 6 6}$ & 0.26 & 0.11 & 0.26 \\
Right renal artery & $\mathbf{0 . 5 1}$ & $\mathbf{0 . 5 1}$ & $\mathbf{0 . 5 3}$ & 0.08 \\
Left renal artery & $\mathbf{0 . 4 3}$ & $\mathbf{0 . 4 6}$ & $\mathbf{0 . 3 5}$ & $\mathbf{0 . 5 3}$ \\
\hline
\end{tabular}

Statistical important differences are presented in bold

presented. No significant differences occur except of loss of statistical significance for several correlations - probably due to sample diminution.

Table 5 presents correlations between SA, RRA, LRA diameter and spleen, right kidney and left kidney morphometry, respectively. These diameters are correlated in a statistical significant manner with viscera weight $(r=0.66,0.51,0.42$, respectively, $p<0.05)$. Also LRA diameter is correlated with left kidney length, width and thickness $(r=0.46,0.35$ and 0.53 , respectively, $p<0.05$ ) as was RRA and right kidney length and width $(r=0.51$ and $0.53, p<0.05$, respectively). Those results were not reproduced for spleen.

Table 6 presents the same correlations stratified for sex. Generally the same correlations are valid with exception of loss of correlation between SA and spleen for women and statistically significant correlation between $\mathrm{SA}$ and spleen length and thickness for men $(r=0.37$ and $0.42, p<0.05$, respectively). Also statistically significant correlation occured between RRA and right kidney thickness $(r=0.50$ for men and 0.53 for women, $p<0.05$ ).

Table 7 presents the same analysis with sample stratification between embalmed and fresh cadavers. As expected, some previously not correlated characteristics were now correlated for fresh cadavers (SA to splenic length, $r=0.44, p<0.05$ and RRA to right kidney length, $r=0.55, p<0.05)$. Notably some correlations were stronger to embalmed cadavers than to whole sample. 
Table 6. Pearson's correlation coefficient between artery diameter and organ morphometry (stratified for men/women)

\begin{tabular}{lcccc}
\hline & Weight & Length & Width & Thickness \\
\hline Splenic artery & $0.72 / 0.22$ & $0.37 /-0.02$ & $0.10 / 0.17$ & $0.34 / 0.12$ \\
Right renal artery & $0.47 / 0.61$ & $0.42 / 0.61$ & $-0.07 / 0.34$ & $0.50 / 0.53$ \\
Left renal artery & $0.49 / 0.57$ & $0.42 / 0.70$ & $0.33 / 0.55$ & $0.50 / 0.73$ \\
\hline
\end{tabular}

Statistical important differences are presented in bold

Table 7. Pearson's correlation coefficient between artery diameter and organ morphometry (stratified for fresh/formalin fix cadavers)

\begin{tabular}{lcccc}
\hline & Weight & Length & Width & Thickness \\
\hline Splenic artery & $\mathbf{0 . 6 6 / N A}$ & $\mathbf{0 . 4 4 / 0 . 2 1}$ & $0.12 / 0.54$ & $0.21 / 0.68$ \\
Right renal artery & $\mathbf{0 . 5 1 / N A}$ & $\mathbf{0 . 5 4 / 0 . 6 8}$ & $-0.05 / 0.51$ & $\mathbf{0 . 5 5 / 0 . 4 2}$ \\
Left renal artery & $\mathbf{0 . 4 3 / N A}$ & $\mathbf{0 . 4 9 / 0 . 6 9}$ & $\mathbf{0 . 3 5 / - 0 . 1 6}$ & $\mathbf{0 . 5 1 / 0 . 7 6}$ \\
\hline
\end{tabular}

Statistical important differences are presented in bold; NA — not available

Age was correlated only to SMA diameter $(r=0.38$, $p<0.05)$, right iliac artery diameter $(r=0.44, p<0.05)$ and left iliac artery diameter $(r=0.42, p<0.05)$ for whole sample. Age was negatively correlated to spleen weight $(r=-0.32, p<0.05)$. Height was negatively correlated to right iliac artery and left iliac artery $(r=-0.04, p<0.05$ and $r=-0.43, p<0.05$, respectively) but positively to spleen weight, right kidney weight and left kidney length $(r=0.22,0.22$ and $0.28, p<0.05$, respectively)

\section{DISCUSSION}

Abdominal aorta branches and viscera morphometry are investigated with different methods, but cadaveric dissection remains the gold standard. Ideal method should be precise, repeatable and objective. It should also be non-invasive, cheap and easily applicable. Morphometry should be studied in healthy subjects under normal circumstances.

Radiologic studies do not satisfy one or more of these requirements. Ultrasound (US) is cheap, easily applicable and non-invasive, yet operator-dependent [88] and prone to magnification effect and diameter overestimation $[20,65,77]$. Not all arteries are visualised due to their anatomic position, including CA, SMA and IMA $[25,59]$. Computerised topographic angiography and magnetic resonance angiography are precise, objective and repeatable $[66,99]$ but method they apply (3-dimensional reconstruction of vessels filled with contrast material) is probably superior for lumen rather than diameter estimation. Also they are usually performed at diseased populations, are relative expensive and not widely available. Classic and digitalised angiography visualises with great precision and objectivity lumen of a vessel but is invasive and also performed in highly selected population, thus unsuitable for normality studies.

To overcome these limitations, some authors [20, 29] performed intraoperative US measurements so to eliminate magnification effect and comprehend all AA branches. While a certain improvement, patients subjected to operation are under vasodilative effects of general anaesthesia and also a highly selected population, thus not proper for normality studies.

Cadaveric studies should fulfil two requirements: A population that can be characterised "normal" except of death changes and understanding that measurements represent the lowest, yet normal, range of arteries diameter. Garby et al. [28] and Songur et al. [94] modulated criteria for autopsy studies that ensure normality, and those were adapted during designing of this study. Briefly, these involve violent or natural death causes that do not affect abdominal vessels, lack of chronic disease that affects vessel wall or calibre, no drug use and short interval ( $<24 \mathrm{~h}$ ) between time of death and autopsy. Same criteria are applicable to embalmed cadavers since their medical history is known and during dissection they can be examined with autopsy methods. As for diameter, arteries are influenced by stimuli that constantly change their diameter. Normal pulsatility affects diameter approximately 6\% [65] while arteries' diameter is subjected to vasodilative and vasoconstrictive stimuli including exercise, meal, intravascular volume changes and, to a lesser extent, to cholinergic and adrenergic stimuli and hormonal regulation [73]. Arteries unlike veins do not collapse due to their wall stiffness and diameters measured at cadavers represent lowest 
normal values. Since all those factors do not change diameter radically and act predictably, those measurements are a very good estimation of "normal". Concerning effects of formaldehyde, most studies $[55,72]$ assume that it does not change vessels' morphometry. To the best of our knowledge, our study is the first to perform statistical comparison in a mixed sample selected under the same criteria and prove this assumption correct. Finally, few studies $[36,72$, 92] have stated that existence of anatomic variation could alter a vessels' morphometry. We have chosen to discard cadavers presenting variations interfering with results of this study.

Abdominal aorta branches morphometry is determinative for many physiological and pathological procedures in human body. Most studies of abdominal circulation provide detailed information for typology, variations and collateral networks but lack of information or provide a very wide range for those measurements $[49,83]$. No statistical comparisons are attempted and data sources are mixed from cadaveric, radiological and surgical studies. Table 8 presents major studies on AA branches' morphometry. Our results are similar yet somewhat larger than those reported in the literature, yet this is expected considering the large number of US studies and the magnification effect known to have. On interpretation of these results it should be considered that radiologic methods (US, computed tomography angiography, angiography) instead of cadaveric or surgical studies measure lumen rather than total arterial diameter.

Celiac artery diameter determines blood flow at spleen, stomach and liver. Celiac artery stenosis is implicated in pathogenesis of median arcuate ligament syndrome manifesting with postprandial pain due to CA compression from median arcuate ligament. Symptoms of the syndrome are attributed to ischaemia [13]. Another explanation is neurogenic pain origin due to direct pressure of celiac ganglion. Cutting of the ligament alleviates symptoms in a number of patients [22]. Also CA acts like an anastomotic network in case of SMA stenosis and its sufficiency is related to its diameter. While other factors are also important, a larger CA could be beneficial.

Common hepatic artery diameter is crucial for hepatobiliary operations including hepatectomy and liver transplantation. Liver grafts supplied by larger arteries present less post-operative complications, including destructive complication of arterial thrombosis, while left or right hepatic artery diameter $<3 \mathrm{~mm}$ is an exclusion donor criterion in some centres [84]. Whether or not existence of anatomic variation is beneficial is controversial. Some authors [84] believe that variations existence is related to smaller diameter and thus less satisfactory results and more complications while others [36] support the opposite. Detailed common hepatic artery morphometry knowledge is necessary for generation of flow models, critical for chemoembolisation procedures and microspheres design [5]. Common hepatic artery diameter increases in some diseases like cirrhosis and alcoholic hepatitis [34].

Detailed morphometry of $S A$ is valuable for study of SA aneurysms. Splenic artery aneurysms are the commonest visceral aneurysms, present in $10.6 \%$ of the population and fatal in $>90 \%$ of cases if ruptured [96]. Therapy with splenectomy or embolisation is advocated if $>20 \mathrm{~mm}$, probable pregnancy or symptomatic aneurysm [8]. Even more SA diameter and SA/hepatic artery diameter is known to increase in SA steal syndrome a complication of liver transplantation [45]. In those cases, embolisation of SA ameliorates liver function [4]. Sato et al. [86] and Zeng et al. [104] proved that SA diameter and SA/ /hepatic artery diameter increases in cirrhosis due to hyperkinetic circulation. Setting calliper cut-off value at $5.2 \mathrm{~mm}$, they stated that splenectomy can ameliorate cirrhosis symptoms.

Morphometry of left gastric artery has not received special attention, probably due to lack of specific clinical application, inaccessibility to radiologic study and rich collateral network of stomach. Visceral aneurysms of left gastric artery are rare and, if ruptured, present a high mortality rate [85].

Superior mesenteric artery diameter has received the attention of the medical literature due to its important role in bowel function and digestion and its important role in manifestation of chronic mesenteric ischaemia and a variety of bowel diseases. Superior mesenteric artery diameter increases with a number of stimuli, including meal $[37,76,90]$ and decreases with exercise [77], cold stimuli [81] and hypovolaemia [74]. Also SMA diameter increases in diseases with enteric manifestation [24], including Crohn's colitis [54, 70] and celiac disease [1]. Major clinical importance of SMA diameter and flow is during evaluation of chronic mesenteric ischaemia. Stent placement at the artery with open or endovascular procedure is a valuable therapeutic option and thus detailed morphometric analysis is necessary for stent design [10]. 
Table 8. Abdominal aorta branches' diameters

\begin{tabular}{|c|c|c|c|c|c|c|c|c|c|}
\hline & Study type & CA & SA & LGA & CHA & SMA & RRA & LRA & IMA \\
\hline Kahn and Abrams, 1964 [39] & CS & & & & & & & & 3.3 \\
\hline Vandamne and Bonte, 1985 [100] & CS & & 8 & 4.2 & & & & & \\
\hline \multirow[t]{2}{*}{ Jager et al., 1986 [37] } & US & & & & & $\mathrm{F}: 6 \pm 0.9$ & & & \\
\hline & & & & & & $P: 6.7 \pm 0.9$ & & & \\
\hline \multirow[t]{2}{*}{ Nicholls et al., 1986 [67] } & US & F: $5.3 \pm 0.8$ & & & & $\mathrm{~F}: 6.4 \pm 0.9$ & & & \\
\hline & & $P: 5.6 \pm 0.08$ & & & & $P: 6.4 \pm 0.8$ & & & \\
\hline Qamar et al., 1986 [77] & US & & & & & $6.7 \pm 0.77$ & & & \\
\hline \multirow[t]{2}{*}{ Sato et al., 1987 [86] } & US & & M: 4.8 & & 4.2 & M: 6.4 & & & \\
\hline & & & W: 4.6 & & & W: 5.6 & & & \\
\hline Moneta et al., 1988 [61] & US & & & & & 5.9 & & & \\
\hline Lilly et al., 1989 [48] & US & $6.3 \pm 0.4$ & & & & $6.3 \pm 0.4$ & & & \\
\hline Braatvedt et al., 1991 [12] & US & & & & & $7.3 \pm 0.2$ & & & \\
\hline Carlisle et al., 1992 [15] & US & & & & 6 & & & & \\
\hline \multirow[t]{2}{*}{ Scheurlen et al., 1992 [88] } & US & & & & & M: $6.5 \pm 1$ & & & \\
\hline & & & & & & W: $5.8 \pm 0.2$ & & & \\
\hline Braatvedt et al., 1993 [11] & US & & & & & 7.8 & & & \\
\hline \multirow[t]{2}{*}{ Delagunt et al., 1996 [20] } & US & l: $7.2 \pm 2.0$ & l: $7.1 \pm 1.5$ & & I: $6.1 \pm 1.6$ & I: $8.3 \pm 2.9$ & & & I: $3.2 \pm 1.3$ \\
\hline & & $\mathrm{T}: 7.7 \pm 2.2$ & $\mathrm{~T}: 5.1 \pm 1.5$ & & $\mathrm{~T}: 5.9 \pm 1.4$ & $\mathrm{~T}: 7.1 \pm 1.9$ & & & $\mathrm{~T}: 2.5 \pm 1.0$ \\
\hline \multirow[t]{2}{*}{ Geelkerken et al., 1998 [30] } & US & I: $6.92 \pm 1.55$ & & & & I: $7.62 \pm 2.02$ & & & \\
\hline & & $\mathrm{T}: 8.4 \pm 2.4$ & & & & $\mathrm{~T}: 8.7 \pm 2.6$ & & & \\
\hline Erden, et al., 1998 [24] & US & & & & & $6.13 \pm 0.89$ & & & $3.1 \pm 0.68$ \\
\hline \multirow[t]{2}{*}{ Geelkerken et al., 1998 [30] } & US & $\mathrm{F}: 7.1 \pm 1.6$ & F: $5.5 \pm 2.40$ & & $F: 5.4 \pm 1.30$ & $\mathrm{~F}: 7.5 \pm 2.10$ & & & $\mathrm{~F}: 2.9 \pm 0.78$ \\
\hline & & P: $7.6 \pm 1.6$ & P: $6.1 \pm 1.4$ & & P: $5.5 \pm 1.6$ & $P: 7.6 \pm 1.6$ & & & P: $3.1 \pm 0.97$ \\
\hline Mirk et al., 1998 [59] & & & & & & & & & $2.8 \pm 0.55$ \\
\hline Machalek et al., 1998 [53] & CS & & $5.6 \pm 1.3$ & & & & & & \\
\hline Quarto Di Palo et al., 2002 [78] & US & & & & & $4.8 \pm 0.7$ & & & \\
\hline Han et al., 2002 [34] & US & & & & $2.68 \pm 0.69$ & & & & \\
\hline \multirow[t]{2}{*}{ Daisy Sahni et al., 2003 [19] } & CS & M: $5.3 \pm 1.2$ & & & & & & & \\
\hline & & W: $4.9 \pm 1.0$ & & & & & & & \\
\hline Sigirci et al., 2003 [91] & US & & & & & & & & $3.2 \pm 0.66$ \\
\hline \multirow[t]{2}{*}{ Singh et al., 2004 [93] } & CS & M: 6.5 & & & M: 5.4 & & & & \\
\hline & & W: 6.7 & & & W: 5.2 & & & & \\
\hline Pennington and Soames, 2005 [72] & CS & $4.9 \pm 1.0$ & & & & $9.1 \pm 2.0$ & $6.8 \pm 1.4$ & $5.2 \pm 1.3$ & $4.5 \pm 1.1$ \\
\hline \multirow[t]{2}{*}{ Ishigami et al., 2005 [36] } & SS & & & & Ty: $6.3 \pm 0.9$ & & & & \\
\hline & & & & & $V: 5.8 \pm 0.8$ & & & & \\
\hline Kirbas et al., 2007 [45] & US & $9.2 \pm 0.7$ & $7.3 \pm 0.6$ & $3.8 \pm 0.1$ & $5.6 \pm 0.5$ & $7.6 \pm 0.4$ & & & \\
\hline Petrell et al., 2007 [75] & CS & $7.6 \pm 0.4$ & $5.3 \pm 0.4$ & & $4.9 \pm 0.2$ & $7.2 \pm 0.4$ & & & \\
\hline \multirow[t]{2}{*}{ Silveira et al., 2009 [92] } & CS & Тy: $7.9 \pm 0.04$ & Ty: $5.3 \pm 0.3$ & Ty: $3.8 \pm 0.3$ & Ty: $5 \pm 0.4$ & & & & \\
\hline & & $V: 7.1 \pm 0.06$ & V: $5.3 \pm 0.4$ & $V: 3.3 \pm 0.3$ & V: $5.2 \pm 0.5$ & & & & \\
\hline \multirow[t]{2}{*}{ Turba et al., 2009 [99] } & CTA & & & & & & M: $5.1 \pm 1.0$ & M:5.1 \pm 0.9 & \\
\hline & & & & & & & W: $4.9 \pm 0.8$ & $W: 4.7 \pm 0.8$ & \\
\hline Tarzamni et al., 2008 [98] & CS & & & & & & $6.1 \pm 1.2$ & $6,2 \pm 1.1$ & \\
\hline Songur et al., 2010 [94] & CS & $6.43 \pm 1.59$ & & & & $7.38 \pm 1.67$ & & & $3.71 \pm 0.72$ \\
\hline O'Flynn et al., 2010 [69] & MRA & 10.04 & & & & 9.09 & 9.01 & 8.89 & \\
\hline \multirow[t]{2}{*}{ Malnar et al., 2010 [55] } & CS & Тy: $7.8 \pm 0.08$ & Ty: $6.1 \pm 0.5$ & Ty: $4.7 \pm 0.2$ & Ty: $5.7 \pm 0.4$ & & & & \\
\hline & & $V: 7.3 \pm 0.07$ & $\mathrm{~V}: 6.1 \pm 0.6$ & V: $4.5 \pm 0.1$ & $V: 5.8 \pm 0.6$ & & & & \\
\hline
\end{tabular}

CA — celiac artery; SA — splenic artery; CHA — common hepatic artery; LGA — left gastric artery; SMA — superior mesenteric artery; RRA — right renal artery; LRA — left renal artery; IMA — inferior mesenteric artery; CS — cadaveric study; US — ultrasound; MRA — magnetic resonance angiography; SS — surgical study; CTA — computerised tomographic angiography; F — fasting; P — postprandial; $\mathrm{M}$ - men; W — women; I — intraabdominal; T — transabdominal; Ty — typical; V — variation 
Renal arteries evaluation is important for a number of diseases and procedures, including renovascular hypertension and renal transplantation. Detailed knowledge of renal arteries diameter is necessary for stent design for treatment of renal artery aneurysm [14] or stenosis [27] and even more for personalised fenestrated or chimney-stent grafts for endovascular aneurysm repair of aneurysms of supra-renal aorta $[38,40,62]$. Morphometry of accessory renal arteries is of special importance because, especially lower poles, vascularise the kidney segmentally alongside with upper ureters and thus should be preserved and anastomosed in case of renal transplantation. According to Satyapal et al. [87] first accessory renal artery has a diameter of approximately $4 \mathrm{~mm}$ and second of $3 \mathrm{~mm}$. According to Tarzamni et al. [98], men have larger renal arteries, a result not reproduced in this study.

Inferior mesenteric artery has not received similar attention, probably due to its relative inaccessibility to ultrasound examination and its secondary role in bowel haematosis. Yet IMA supports important collateral network and is capable of increasing its diameter in case of CA, SMA or iliac arteries occlusion [24]; thus, detailed morphometric knowledge could aid in its sufficiency calculation in case of occlusive diseases.

To the best of our knowledge, correlations between AA branches have never been investigated before. In this study, we found significant correlations between CA branches, CA and SMA and iliac arteries and other branches. Since haematosis of corresponding viscera of CA branches is independent to other branches, we do not believe that this is due to harmonisation of demands between viscera but we rather believe that this is due to a common embryological factor that induces homogenous development. Embryologically, mesenteric circulation develops from the primitive ventral segmental arteries: $10^{\text {th }}, 11^{\text {th }}$ and $12^{\text {th }}$ give rise to CA and its branches, $13^{\text {th }}$ to SMA and $22^{\text {nd }}$ to IMA. Persistence or regression of those branches gives rise to anatomic variations [50,83]. It is unknown whether variations are induced from random events, genetic factors or meditators' action. Blood vessels begin to form during third week of embryonic life. Angioblasts give rise to endothelial cells and then secondary endothelial cells develop from pre-existing ones. Mechanism like sprouting, intussusception, vessel elongation and incorporation of circulating endothelial progenitor cells into growing vessels have been investigated in cellular level [102] alongside with action of various genes and meditators. Angiogenesis depends on balance between vasculogenesis promotion and inhibiting factors, like vascular endothelial growth factor, fibroblasts growth factor and tumour necrosis factor [46]. While unable to provide complete explanation, we believe that this homogeneity deflects theory of rare events at least in macroscopic vasculogenesis.

Spleen and kidney morphometry have been thoroughly studied. Most studies investigated autopsy material and are thus influenced by inclusion of many diseased subjects. Strict inclusion criteria resembling ours were used by Garby et al. [28], Murty et al. [63] and Molina et al. [60]. Their results are presented in Table 9. Our results are similar to theirs while other studies' results vary ranging from $96 \mathrm{~g}$ [56] to $240 \mathrm{~g}$ [35] for spleen weight and from $125 \mathrm{~g}$ [56] to $185 \mathrm{~g}$ [35] for kidney weight. Viscera weight increases with male sex, height and weight while decreases with age but only after 40 . There is great discrepancy of data on the extent of the correlation [17, 28, 33, 44, 60, 95]. Differences between races and nationalities have also been investigated $[6,57,63]$ with variable results. Viscera' morphometric characteristics from largest studies are presented at Tables 10 and 11. Disparity between results is smaller probably because most studies are US studies in selected, healthy populations. Results in viscera dimensions measurement are probably more reliable in US studies than those of arteries because of their greater dimensions, more superficial position and constant size $[26,51]$. Our results are in concordance with those of the literature. Our results also show that viscera dimensions are smaller in a statistically important level between fresh and embalmed cadavers, making the latter inappropriate for morphometric studies.

Spleen and kidney length have both been correlated to their functionality and pathologic status. Spleen size increases in many infectious diseases and haematological malignancies while one kidney can enlarge so to cover the other's deficiency [31]. Spleen length has been proposed as a measure of its volume [9] and thus precise knowledge or its normal values is valuable. Kidney volume is important for staging of renovascular hypertension, chronic renal insufficiency and transplantation [3, 80]. Even more length has been weakly yet constantly and directly correlated with creatinine levels and glomerular filtration rate in transplanted patients, making it an appropriate examination for follow-up of patients with known renal insufficiency $[7,71,97,101]$. Viscera width and 
Table 9. Viscera weight

\begin{tabular}{lcccc}
\hline Study & \multicolumn{2}{c}{ Spleen } & \multicolumn{2}{c}{ Kidneys } \\
\cline { 2 - 5 } & Men & Women & Men & Women \\
\hline Garby et al., 1993 [28] & 167 & 127 & 173 & 130 \\
Murty et al., 2007 [63] & 124 & 129 & 132 & 126 \\
Molina and DiMaio, 2012 [60] & 139 & & 130 & \\
\hline
\end{tabular}

Table 10. Spleen morphometric characteristics

\begin{tabular}{lcccc}
\hline Author & Study type & Length & Width & Thickness \\
\hline Larson et al., 1971 [47] & Nuc & $10 \pm 1.5$ & $7.1 \pm 1.6$ & $4.93 \pm 1.17$ \\
Cools et al., 1983 [18] & CT & $7.56 \pm 3.32$ & $9.55 \pm 2.55$ & $2.8 \pm 0.7$ \\
Rodrigues et al., 1995 [82] & Nuc & $11.1 \pm 2$ & $8.8 \pm 1.7$ & 4.01 \\
De Odorico et al., 1999 [68] & US & 8.94 & & \\
Loftus et al., 1999 [52] & US & $8.84 \pm 2.0$ & & $5 \pm 0.9$ \\
Shin et al., 2009 [89] & US & $9.58 \pm 1.22$ & $4.6 \pm 1.2$ & \\
Mustapha et al., 2010 [64] & US & $8.9 \pm 1.3$ & & \\
\hline
\end{tabular}

US — ultrasound; CT — computerised tomography; Nuc — nuclear

Table 11. Kidney morphometric characteristics

\begin{tabular}{|c|c|c|c|c|c|}
\hline Author & & Study type & Length & Width & Thickness \\
\hline \multirow[t]{2}{*}{ Larson et al., 1971 [47] } & $\mathrm{R}$ & \multirow{2}{*}{ US } & 9.32 & & \\
\hline & $\mathrm{L}$ & & 9.62 & & \\
\hline \multirow[t]{2}{*}{ Emamian et al., 1993 [23] } & $\mathrm{R}$ & \multirow{2}{*}{ US } & 11.2 & 5.9 & \\
\hline & L & & 10.9 & 5.8 & \\
\hline \multirow[t]{2}{*}{ Miletic et al., 1998 [58] } & $\mathrm{R}$ & \multirow{2}{*}{ US } & $11.2 \pm 0.9$ & & \\
\hline & $\mathrm{L}$ & & $11.0 \pm 0.9$ & & \\
\hline \multirow[t]{2}{*}{ Bakker et al., 1999 [3] } & & \multirow[t]{2}{*}{ US } & 11.19 & & \\
\hline & & & 11.46 & & \\
\hline Widjaja et al., 2004 [101] & & US & 9.91 & & \\
\hline \multirow[t]{2}{*}{ Cheong et al., 2007 [16] } & M & \multirow{2}{*}{ MRI } & $12.4 \pm 0.9$ & & \\
\hline & W & & $11.6 \pm 1.1$ & & \\
\hline Kang et al., 2007 [42] & & Autopsy & $11.1 \pm 1.0$ & $6.25 \pm 0.67$ & $4.73 \pm 0.63$ \\
\hline \multirow[t]{2}{*}{ Glodny et al., 2009 [31] } & $\mathrm{R}$ & \multirow{2}{*}{ MDCT } & $10.8 \pm 1.1$ & $5.13 \pm 0.78$ & \\
\hline & $\mathrm{L}$ & & $11.1 \pm 1.3$ & $5.33 \pm 0.82$ & \\
\hline \multirow[t]{2}{*}{ Shin et al., 2009 [89] } & $\mathrm{R}$ & \multirow{2}{*}{ MDCT } & $10.7 \pm 0.76$ & & \\
\hline & L & & $10.9 \pm 0.72$ & & \\
\hline \multirow[t]{2}{*}{ Arooj et al., 2011 [2] } & $\mathrm{R}$ & \multirow{2}{*}{ US } & $9.79 \pm 0.9$ & $3.8 \pm 0.52$ & $3.8 \pm 0.37$ \\
\hline & $\mathrm{L}$ & & $9.9 \pm 0.96$ & $4.4 \pm 0.59$ & $4.3 \pm 0.79$ \\
\hline \multirow[t]{2}{*}{ Surcel et al., 2011 [97] } & $\mathrm{R}$ & \multirow{2}{*}{ US } & $10.75 \pm 1.1$ & $5.19 \pm 0.58$ & $5.37 \pm 0.38$ \\
\hline & L & & $11.83 \pm 1.23$ & $5.17 \pm 0.82$ & $5.29 \pm 0.82$ \\
\hline
\end{tabular}

US — ultrasound; MRI — magnetic resonance imaging; MDCT — multidetector computerised tomography; $\mathrm{R}$ - right; L — left; $\mathrm{M}$ — men; W — women 
thickness do not present direct clinical importance, yet they are necessary for calculating spleen [68, 103] and kidney [23] volume. Spleen length is known to increase with male sex, height and weight and decrease with age although level of correlation varies across various studies [21, 41]. Kidney length is also known to increase with male sex, height and weight and decrease with age after the age of 50 [31, 32, $42,89,97]$. Kasiske and Umen [43] support that, for kidney, correlation exists only between organ weight and body surface area.

Pearson's correlation coefficient between age, spleen weight, spleen length, kidney weight and kidney length were $-0.32, p<0.05,-0.29, p>0.05$, $-0.09, p>0.05$ and $-0.21, p>0.05$ respectively. Pearson's correlation coefficient between, height, spleen weight, spleen length, kidney weight and kidney length were $0.27, p<0.05,0.21, p>0.05,0.22$, $p<0.05$ and $0.13, p>0.05$. Those values are similar to those of the literature yet due to small sample size, they do not reach statistical significance. Even more, we investigated a new correlation between regional artery diameter and viscera morphometry, including weight and length. Possible explanations are an increase in viscera size due to better haematosis or an artery diameter increase due to higher demands or a common, probably embryologic, factor determining both. It is difficult in the context of this study to select an explanation. Yet since larger organs might be advantageous, further research is required so to clarify this novel correlation

\section{Limitations of the study}

Main limitation of this study is its relative small sample. Sample size is appropriate for statistical calculations and comparison but renders difficult its division in sub-population. Second limitation is that diameters were measured at the origin of each artery and not at its termination. Arterial branches could lead to vessels tapering and thus smaller diameter at their termination. However taking in consideration relative small size of those branches, i.e. adrenal arteries and pancreatic arteries, we believe the difference is insignificant.

\section{CONCLUSIONS}

Abdominal aorta branches and corresponding viscera morphometry is of anatomical, clinical and embryological interest. Many common diseases like chronic renal insufficiency, infection and haematological diseases but also uncommon ones like various transplantation complication affect morphometric characteristics of viscera and thus those acquire diagnostic and therapeutic importance. It is probably more difficult to investigate arterial morphometry because of aforementioned technical limitations, yet applications are numerous and include common diseases like inflammatory bowel diseases and chronic mesenteric stenosis but also rarer ones like SA aneurysm.

Apart from diagnostic, therapeutic results can be evaluated using this methodology. A number of medical, interventional and surgical procedures including vasodilating drugs, stents placement and anastomoses adequacy for transplantation can be approached through arterial and visceral morphometry.

Embryologic factors determining those measures are not completely understood. In summary, current study: (1) Offers detailed morphometric data in a selected sample, approaching normality. (2) Performs original statistical analysis and comparisons between subpopulations and extracts useful results including suitability of embalmed cadavers for arteries' morphometric study but unsuitability for organs' morphometric studies. (3) Discovers correlations between AA branches and a previously unreported correlation between regional arteries and corresponding viscera' morphometry. (4) Puts the above conclusions in an anatomical, embryological and clinical context.

\section{Authors' contribution}

A.M. conducted the study, reviewed the literature and participated in writing of the manuscript; N.G. conducted the study, reviewed the literature and participated in writing of the manuscript; C.S. conducted the study and performed statistical analysis; N.N. reviewed the literature and participated in manuscript writing; P.S. reviewed the literature and corrected the manuscript; V.G. performed statistical analysis and corrected the manuscript; T.T. conducted the study, performed literature review, participated in manuscript writing and gave his final approval.

\section{REFERENCES}

1. Arienti V, Califano C, Brusco G, Boriani F, Biagi L, Giulia Sama M, Sottili S, Domanico A, Corazza G, Gasbarrini G (1996) Doppler ultrasonographic evaluation of splanchnic blood flow in coeliac disease. Gut, 39: 369-373.

2. Arooj A, Lam J, Wui Y, Supriyanto E (2011) Comparison of Renal Size among Different Ethnicities. Int J Biol Biomed Eng, 5: 221-229. 
3. Bakker J, Olree M, Kaatee R, de Lange E, Moons K, Beutler J, Beek F (1999) Renal volume measurements: accuracy and repeatability of US compared with that of MR imaging. Radiology, 211: 623-628.

4. Bárcena R, Moreno A, Foruny JR, Moreno A, Sanchez J, Gil-Grande L, Blasquez J, Nuno J, Fortun J, Rodriguez-Gandia M, Oton E (2006) Improved graft function in liver-transplanted patients after partial splenic embolization: reversal of splenic artery steal syndrome? Clin Transplant, 20: 517-523. doi: 10.1111/j.1399-0012.2006.00516.x.

5. Basciano CA, Kleinstreuer C, Kennedy AS, Dezarn WA, Childress E (2010) Computer modeling of controlled microsphere release and targeting in a representative hepatic artery system. Ann Biomed Eng, 38: 1862-1879. doi:10.1007/s10439-010-9955-z.

6. Bean R (1926) Composite study of weight of vital organs in man. Am J Phys Antrh, 9: 293-320.

7. Beland MD, Walle NL, Machan JT, Cronan JJ (2010) Renal cortical thickness measured at ultrasound: is it better than renal length as an indicator of renal function in chronic kidney disease? AJR Am J Roentgenol, 195: W146-W149. doi:10.2214/AJR.09.4104.

8. Berceli SA (2005) Hepatic and splenic artery aneurysms. Semin Vasc Surg, 18: 196-201. doi: 10.1053/j.semvascsurg.2005.09.005.

9. Bezerra AS, D'Ippolito G, Faintuch S, Szejnfeld J, Ahmed M (2005) Determination of splenomegaly by CT: is there a place for a single measurement? AJR Am J Roentgenol, 184: 1510-1513.

10. Blauw JTM, Meerwaldt R, Brusse-Keizer M, Kolkman J, Keritas J, Geelkerken R (2014) Retrograde open mesenteric stenting for acute mesenteric ischemia. J Vasc Surg, 60: 726-734. doi:10.1016/j.jvs.2014.04.001.

11. Braatvedt GD, Flynn MD, Stanners A, Halliwell M, Corrall RJ (1993) Splanchnic blood flow in man: evidence for mediation via a beta-adrenergic mechanism. Clin Sci, 84: 201-207.

12. Braatvedt GD, Newrick PG, Halliwell M, Wells PN, Read AE, Corrall RJ (1991) Splanchnic haemodynamic changes during acute hypoglycaemia in man. Clin Sci, 81: 519-524.

13. Brandt $\sqcup$, Boley SJ (1978) Celiac axis compression syndrome. A critical review. Am J Dig Dis, 23: 633-640.

14. Campbell JE, Stone PA, Bates MC (2013) Technical discussion of diagnostic angiography and intervention of atherosclerotic renal artery stenosis. Semin Vasc Surg, 26: 150-160. doi: 10.1053/j.semvascsurg.2014.06.002.

15. Carlisle KM, Halliwell M, Read AE, Wells PN (1992) Estimation of total hepatic blood flow by duplex ultrasound. Gut, 33: 92-97.

16. Cheong B, Muthupillai R, Rubin MF, Flamm SD (2007) Normal values for renal length and volume as measured by magnetic resonance imaging. Clin J Am Soc Nephrol, 2: 38-45. doi: 10.2215/CJN.00930306.

17. Chirachariyavej T, Ouyswat K, Sanggarnjanavanich S, Tiensuwan M, Peonim V, Sirikulchayanonta V (2006) Normal internal organ weight of Thai adults correlated to body length and body weight. J Med Assoc Thai, 89: 1702-1712.

18. Cools L, Osteaux M, Divano L, Jeanmart L (1983) Prediction of splenic volume by a simple CT measurement: a statistical study. J Comput Assist Tomogr, 7: 426-430.

19. Daisy Sahni A, Indar Jit B, Gupta CNM, Gupta DM, Harjeet E (2003) Branches of the splenic artery and splenic arterial segments. Clin Anat, 16: 371-377. doi:10.1002/ca.10172.

20. Delahunt TA, Geelkerken RH, Hermans J, Van Baalen JM, Vaughan AJ, Hajo Van Bockel J (1996) Comparison of trans- and intra-abdominal duplex examinations of the splanchnic circulation. Ultrasound Med Biol, 22: 165-171.
21. DeLand FH (1970) Normal spleen size. Radiology, 97: 589-592.

22. Douard R, Ettorre GM, Chevallier J-M, Delmas V, Cugnenc P-H, Belghiti J (2002) Celiac trunk compression by arcuate ligament and living-related liver transplantation: a two-step strategy for flow-induced enlargement of donor hepatic artery. Surg Radiol Anat, 24: 327-331. doi: 10.1007/ s00276-002-0073-y.

23. Emamian SA, Nielsen MB, Pedersen JF, Ytte L (1993) Kidney dimensions at sonography: correlation with age, sex, and habitus in 665 adult volunteers. Am J Roentgenol, 160: 83-86.

24. Erden A, Cumhur T, Olçer T (1998) Superior mesenteric artery blood flow in patients with small bowel diseases: evaluation with duplex Doppler sonography. J Clin Ultrasound, 26: 37-41.

25. Erden A, Yurdakul M, Cumhur T (1998) Doppler waveforms of the normal and collateralized inferior mesenteric artery. Am J Roentgenol, 171: 619-627.

26. Ferrer FA, McKenna PH, Bauer MB, Miller SF (1997) Accuracy of renal ultrasound measurements for predicting actual kidney size. J Urol, 157: 2278-2281.

27. Gandini R, Morosetti D, Chiocchi M, Chiaravalloti A, Citraro A, Loreni G, Da Ros V, Simonetti G (2014) Long-term follow-up of endovascular treatment of renal artery aneurysms with covered stent deployment. J Cardiovasc Surg (Torino), Dec 5. [Epub ahead of print].

28. Garby L, Lamert O, Kock K, Thobo-Carlsen B (1993) Weights of brain, heart, liver, kidneys, and spleen in healthy and apparently healthy adult danish subjects. Am J Hum Biol, 5: 291-296.

29. Geelkerken RH, Delahunt TA, Schultze Kool $\sqcup$, van Baalen JM, Hermans J, van Bockel JH (1996) Pitfalls in the diagnosis of origin stenosis of the coeliac and superior mesenteric arteries with transabdominal color duplex examination. Ultrasound Med Biol, 22: 695-700.

30. Geelkerken RH, Lamers CB, Delahunt TA, Hermans J, Zwijsen JH, van Bockel JH (1998) Duodenal meal stimulation leads to coeliac artery vasoconstriction and superior mesenteric artery vasodilatation: an intra-abdominal ultrasound study. Ultrasound Med Biol, 24: 1351-1356.

31. Glodny B, Unterholzner V, Taferner B, Hofmann K, Rehder P, Strasak A, Petersern J (2009) Normal kidney size and its influencing factors: a 64-slice MDCT study of 1.040 asymptomatic patients. BMC Urol, 9: 19. doi: 10.1186/1471-2490-9-19.

32. Gourtsoyiannis N, Prassopoulos P, Cavouras D, Pantelidis N (1990)The thickness of the renal parenchyma decreases with age: a CT study of 360 patients. Am J Roentgenol, 155: 541-544.

33. De la Grandmaison GL, Clairand I, Durigon M (2001) Organ weight in 684 adult autopsies: new tables for a Caucasoid population. Forensic Sci Int, 119: 149-154.

34. Han S-HB, Rice S, Cohen SM, Reynolds TB, Fong T-L (2002) Duplex Doppler ultrasound of the hepatic artery in patients with acute alcoholic hepatitis. J Clin Gastroenterol, 34: 573-577.

35. He Q, Heshka S, Albu J, Boxt K, Kranow N, Elia M, Galaggher D (2009) Smaller organ mass with greater age, except for heart. J Appl Physiol, 106: 1780-1784. doi: 10.1152/japplphysiol.90454.2008.

36. Ishigami K, Zhang Y, Rayhill S, Katz D, Stolpen A (2004) Does variant hepatic artery anatomy in a liver transplant recipient increase the risk of hepatic artery complications after transplantation? Am J Roentgenol, 183: 1577-1584.

37. Jäger K, Bollinger A, Valli C, Ammann R (1986) Measurement of mesenteric blood flow by duplex scanning. J Vasc Surg, 3: 462-469.

38. Jones SM, Poole RJ, How TV, Williams R, McWilliams R, Brennan J, Vallabhaneni S, Fisher R (2014) Computational 
fluid dynamic analysis of the effect of morphologic features on distraction forces in fenestrated stent grafts. J Vasc Surg, 60: 1648-1656.e1. doi: 10.1016/j.jvs.2014.08.077.

39. Kahn P, Abrams H (1964) Inferior mesenteric arterial patterns; An angiographic study Radiology, 82: 429-442.

40. Kandail H, Hamady M, Xu XY (2014) Patient-specific analysis of displacement forces acting on fenestrated stent grafts for endovascular aneurysm repair. J Biomech, 47: 3546-3554. doi: 10.1016/j.jbiomech.2014.08.011.

41. Kaneko J, Sugawara Y, Matsui Y, Makuuchi M (2008) Spleen size of live donors for liver transplantation. Surg Radiol Anat, 30: 515-518. doi: 10.1007/s00276-008-0364-z.

42. Kang K-Y, Lee YJ, Park SC, Yang C, Kim Y, Moon I, Koh Y, Bang B, Choi B (2007) A comparative study of methods of estimating kidney length in kidney transplantation donors. Nephrol Dial Transplant, 22: 2322-2327. doi: 10.1093/ndt/gfm192.

43. Kasiske BL, Umen AJ (1986) The influence of age, sex, race, and body habitus on kidney weight in humans. Arch Pathol Lab Med, 110: 55-60.

44. Kim Y, Dim D, Cho S, Yang K (2009) Statistical Analysis for Organ Weights in Korean Adult Autopsies. Korean J Anat, 42: 219-224.

45. Kirbas I, Ulu EMK, Ozturk A, Coskun M, Harman A, Ogus E, Haberal M (2007) Multidetector computed tomographic angiography findings of splenic artery steal syndrome in liver transplantation. Transplant Proc, 39: 1178-1180. doi: 10.1016/j.transproceed.2007.02.024.

46. Kuwano M, Fukushi J, Okamoto M, Nishie A, Goto H, Ishibashi T, Ono M (2001) Angiogenesis factors. Intern Med, 40: 565-572.

47. Larson SM, Tuell SH, Moores KD, Nelp WB (1971) Dimensions of the normal adult spleen scan and prediction of spleen weight. J Nucl Med, 12: 123-126.

48. Lilly MP, Harward TR, Flinn WR, Blackburn DR, Astleford PM, Yao JS (1989) Duplex ultrasound measurement of changes in mesenteric flow velocity with pharmacologic and physiologic alteration of intestinal blood flow in man. J Vasc Surg, 9: 18-25.

49. Lin A, Abu-Isa E, Griffith KA, Ben-Josef E (2008) Toxicity of radiotherapy in patients with collagen vascular disease. Cancer, 113: 648-653. doi: 10.1002/cncr.23591.

50. Lin PH, Chaikof EL (2000) Embryology, anatomy, and surgical exposure of the great abdominal vessels. Surg Clin North Am, 80: xiv, 417-433.

51. Li P-S, Ying M, Chan K-H, Chan P-W, Chu K-L (2004) The reproducibility and short-term and long-term repeatability of sonographic measurement of splenic length. Ultrasound Med Biol, 30: 861-866. doi: 10.1016/j.ultrasmedbio.2004.05.012.

52. Loftus WK, Chow LT, Metreweli C (1999) Sonographic measurement of splenic length: correlation with measurement at autopsy. J Clin Ultrasound, 27: 71-74.

53. Machálek L, Holibková A, Tưma J, Houserková D (1998) The size of the splenic hilus, diameter of the splenic artery and its branches in the human spleen. Acta Univ Palacki Olomuc Fac Med, 141: 45-48.

54. Maconi G, Parente F, Bollani S, Imbesi V, Ardizzone S, Russo A, Bianchi Porro G. Factors affecting splanchnic haemodynamics in Crohn's disease: a prospective controlled study using Doppler ultrasound. Gut, 43: 645-650.

55. Malnar D, Klasan GS, Miletić D, Bajek S, Vranic T, Arbanas J, Bobinac D, Cocklo M (2010) Properties of the celiac trunk: anatomical study. Coll Antropol, 34: 917-921.

56. Mathuramon $P$, Chirachariyavej T, Peonim AVMV, Rochanawutanon M (2009) Correlation of internal organ weight with body weight and length in normal Thai adults. J Med Assoc Thai, 92: 250-258.
57. McCormick W, Kashgarian M (1965) The weight of the adult human spleen. J Clin Pathol, 1965; 43: 332-333.

58. Miletić D, Fuckar Z, Sustić A, Mozetic V, Stimac D, Zauhar G (1986) Sonographic measurement of absolute and relative renal length in adults. J Clin Ultrasound, 26: 185-189.

59. Mirk P, Palazzoni G, Cotroneo AR, di Stasi C, Fileni A (1998) Sonographic and Doppler assessment of the inferior mesenteric artery: normal morphologic and hemodynamic features. Abdom Imaging, 23: 364-369.

60. Molina DK, DiMaio VJM (2012) Normal organ weights in men: part ii-the brain, lungs, liver, spleen, and kidneys. Am J Forensic Med Pathol, 2012; 33: 368-372. doi:10.1097/ PAF.0b013e31823d29ad.

61. Moneta GL, Taylor DC, Helton WS, Mulholland MW, Strandness DE Jr (1988) Duplex ultrasound measurement of postprandial intestinal blood flow: effect of meal composition. Gastroenterology, 95: 1294-1301.

62. Moulakakis KG, Mylonas SN, Avgerinos E, Pappetrou A, Kakisis J, Brountzos E, Liapis C (2012) The chimney graft technique for preserving visceral vessels during endovascular treatment of aortic pathologies. J Vasc Surg, 55: 1497-1503. doi: 10.1016/j.jvs.2011.10.009.

63. Murty O, Ling C, Suhashni G, Mohd Fahmee A, Nurasma Z, Khalsom S (2007) Organ weights of Malay, Chinese, Indian, and Indonesian ethnic groups in Malaysia. Mal J For Path Sci, 2: 53-84.

64. Mustapha Z, Tahir A, Tukur M, Bukar M, Lee W-K (2010) Sonographic determination of normal spleen size in an adult African population. Eur J Radiol, 75: e133-135. doi: 10.1016/j.ejrad.2009.09.025.

65. Nakamura T, Moriyasu F, Ban N, Nishida O, Tamada T, Kawasaki T, Sakai M, Uchino H (1989) Quantitative measurement of abdominal arterial blood flow using image-directed Doppler ultrasonography: superior mesenteric, splenic, and common hepatic arterial blood flow in normal adults. J Clin Ultrasound, 17: 261-268.

66. Nghiem HV, Dimas CT, McVicar JP, Perkins J, Luna J, Winter T, Harris A, Freeny P (1999) Impact of double helical CT and three-dimensional CT arteriography on surgical planning for hepatic transplantation. Abdom Imaging, 24: 278-284.

67. Nicholls S, Kohler T, Martin R, Strandness D (1986) Use of hemodynamic parametrs in the diagnosis of mesenteric insufficiency. J Vasc Surg, 3: 507-510.

68. De Odorico I, Spaulding KA, Pretorius DH, Lev-Toaff AS, Bailey TB, Nelson TR (1999) Normal splenic volumes estimated using three-dimensional ultrasonography. J Ultrasound Med, 18: 231-236.

69. O'Flynn PM, O'Sullivan G, Pandit AS (2010) Geometric variability of the abdominal aorta and its major peripheral branches. Ann Biomed Eng, 38: 824-840. doi: 10.1007/ s10439-010-9925-5.

70. Van Oostayen JA, Wasser MN, van Hogezand RA, Griffioen G, de Roos A (1994) Activity of Crohn disease assessed by measurement of superior mesenteric artery flow with Doppler US. Radiology, 193: 551-554.

71. Paleologo G, Abdelkawy H, Barsotti M, Basha A, Bernabini G, Bianchi A, Caprio F, Emad A, Grassi G, Nerucci B, Tregnaghi C, Rizzo G, Donadio C (2007) Kidney dimensions at sonography are correlated with glomerular filtration rate in renal transplant recipients and in kidney donors. Transplant. Proc, 39: 1779-1781. doi: 10.1016/j.transproceed.2007.05.003.

72. Pennington N, Soames RW (2005) The anterior visceral branches of the abdominal aorta and their relationship to the renal arteries. Surg Radiol Anat, 27: 395-403. doi: 10.1007/s00276-005-0026-3.

73. Perko MJ. (2001) Duplex ultrasound for assessment of superior mesenteric artery blood flow. Eur J Vasc Endovasc Surg, 21: 106-117. doi: 10.1053/ejvs.2001.1313. 
74. Perko MJ, Perko G, Just S, Secher NH, Schroeder TV (1996) Changes in superior mesenteric artery Doppler waveform during reduction of cardiac stroke volume and hypotension. Ultrasound Med Biol, 22: 11-18.

75. Petrella S, Rodriguez C, Sgrott EA, Fernandes G, Marques SR, Prates JC (2007) Anatomy and Variations of the Celiac Trunk. Int J Morphol, 25: 249-257.

76. Qamar MI, Read AE (1988) Effects of ingestion of carbohydrate, fat, protein, and water on the mesenteric blood flow in man. Scand J Gastroenterol, 23: 26-30.

77. Qamar MI, Read AE, Skidmore R, Evans JM, Wells PN (1986) Transcutaneous Doppler ultrasound measurement of superior mesenteric artery blood flow in man. Gut, 27: 100-105.

78. Quarto Di Palo F, Rivolta R, Berruti V, Caronni M, Bazzi S, Scorza R (2002) Superior mesenteric artery blood flow in systemic sclerosis patients. Rheumatology (Oxford), 41: 730-734.

79. Qutub AA, Popel AS (2009) Elongation, proliferation \& migration differentiate endothelial cell phenotypes and determine capillary sprouting. BMC Syst Biol, 3: 13. doi: 10.1186/1752-0509-3-13.

80. Rasmussen SN, Haase L, Kjeldsen H, Hancke S (1978) Determination of renal volume by ultrasound scanning. J Clin Ultrasound, 6: 160-164.

81. Ray-Chaudhuri K, Ryder SA, Thomaides T, Mathias CJ (1994) The relationship between blood flow and pulsatility index in the superior mesenteric artery at rest and during constrictor stimuli in normal subjects. J Clin Ultrasound, 22: 149-160.

82. Rodrigues Júnior AJ, Rodrigues CJ, Germano MA, Rasera Júnior I, Cerri GG (1995) Sonographic assessment of normal spleen volume. Clin Anat, 8: 252-255. doi:10.1002/ ca. 980080403

83. Rosenblum JD, Boyle CM, Schwartz LB (1997) The mesenteric circulation. Anatomy and physiology. Surg Clin North Am, 77: 289-306.

84. Sakamoto $Y$, Takayama T, Nakatsuka T, Asato $H$, Sugawara $Y$, Sano K, Imamura H, Kawarasaki H, Makuuchi M (2002) Advantage in using living donors with aberrant hepatic artery for partial liver graft arterialization. Transplantation, 74: 518-521.

85. Sasaki A, Bandoh T, Shiraishi N, Adachi Y, Kitano S, Kaketani K (2001) Laparoscopic ligation of an aneurysm of the left gastric artery. Surg Laparosc Endosc Percutan Tech, 11: 225-227.

86. Sato S, Ohnishi K, Sugita S, Okuda K (1987) Splenic artery and superior mesenteric artery blood flow: nonsurgical Doppler US measurement in healthy subjects and patients with chronic liver disease. Radiology, 164: 347-352.

87. Satyapal KS, Haffejee AA, Singh B, Ramsaroop L, Robbs JV, Kalideen JM (2001) Additional renal arteries: incidence and morphometry. Surg Radiol Anat, 23: 33-38.

88. Scheurlen M, Waller C, Hartmann F (1992) In vivo validation of image-directed Doppler measurement of superior mesenteric artery blood flow. J Clin Ultrasound, 20: 19-26.
89. Shin HS, Chung BH, Lee SE, Kim WJ, Ha HI, Yang CW (2009) Measurement of kidney volume with multi-detector computed tomography scanning in young Korean. Yonsei Med J, 50: 262-265. doi:10.3349/ymj.2009.50.2.262.

90. Sieber C, Beglinger C, Jäger K, Stalder GA (1992) Intestinal phase of superior mesenteric artery blood flow in man. Gut, 33: 497-501.

91. Siğirci A, Senol M, Aydin E, Kutlu R, Arkan A, Atinok T, Yologlu S, Baysal T, Sarac K (2003) Doppler waveforms and blood flow parameters of the superior and inferior mesenteric arteries in patients having Behçet disease with and without gastrointestinal symptoms: preliminary data. J Ultrasound Med, 22: 449-457.

92. Silveira LA da, Silveira FBC, Fazan VPS (2003) Arterial diameter of the celiac trunk and its branches. Anatomical study. Acta Cir Bras, 24: 43-47.

93. Singh D, Bansal Y, Sreenivas M, Pnadery N, Tyagi S (2004) Weights of human organs at autopsy in chandigarh zone of north-west india. IJAFM, 26: 97-99.

94. Songur A, Toktas M, Alkoc O, Akar T, Uzun I, Bas O, Ozen O (2010) Abdominal aorta and its branches: morphometry: variations in autopsy cases. Eur J Gen Med, 7: 321-325.

95. Sprogøe-Jakobsen S, Sprogøe-Jakobsen U (1997) The weight of the normal spleen. Forensic Sci Int, 88: 215-223.

96. Sunagozaka H, Tsuji H, Mizukoshi E, Arai K, Kagaya T, Yamashita T, Sakai A, Nakamoto Y, Honda M, Kaneko S (2006) The development and clinical features of splenic aneurysm associated with liver cirrhosis. Liver Int, 26: 291-297. doi: 10.1111/j.1478-3231.2005.01231.x.

97. Surcel C, Mirvald C, Gingu C, Udrea A, Savu C, Sinescu I (2011) Morphological aspects of the kidney: can normality be predicted? Rom J Morphol Embryol, 52: 1325-1330.

98. Tarzamni MK, Nezami N, Rashid RJ, Argani H, Hajealioghli P, Ghorashi S (2008) Anatomical differences in the right and left renal arterial patterns. Folia Morphol, 67: 104-110.

99. Turba UC, Uflacker R, Bozlar U, Hagspiel KD. (2009) Normal renal arterial anatomy assessed by multidetector $\mathrm{CT}$ angiography: are there differences between men and women? Clin Anat, 22: 236-242. doi: 10.1002/ca.20748.

100. Vandamme JP, Bonte J (1985) The branches of the celiac trunk. Acta Anat (Basel), 122: 110-114.

101. Widjaja E, Oxtoby JW, Hale TL, Jones PW, Harden PN, McCall IW (2004) Ultrasound measured renal length versus low dose CT volume in predicting single kidney glomerular filtration rate. Br J Radiol, 77: 759-764.

102. Wilting J, Christ B (1996) Embryonic angiogenesis: a review. Naturwissenschaften, 83: 153-164.

103. Yetter EM, Acosta KB, Olson MC, Blundell K (2003) Estimating splenic volume: sonographic measurements correlated with helical CT determination. Am J Roentgenol, 181: 1615-1620.

104.Zeng D-B, Dai C-Z, Lu S-C, He N, Wang W, Li H-J (2013) Abnormal splenic artery diameter/hepatic artery diameter ratio in cirrhosis-induced portal hypertension. World J Gastroenterol, 19: 1292-1298. doi: 10.3748/wjg.v19. i8.1292. 